\title{
Surgery for pancreatic cancer: recent progress and future directions
}

\author{
Zachary J. Brown, Jordan M. Cloyd \\ Department of Surgery, The Ohio State University Wexner Medical Center, Columbus, OH, USA \\ Correspondence to: Jordan M. Cloyd, MD. Assistant Professor of Surgery, Division of Surgical Oncology, The Ohio State University Wexner Medical \\ Center, 410 W 10th Ave, N-907 Doan Hall, Columbus, OH 43210, USA. Email: jordan.cloyd@osumc.edu. \\ Comment on: Mizrahi JD, Surana R, Valle JW, et al. Pancreatic cancer. Lancet 2020;395:2008-20.
}

Submitted Jan 15, 2021. Accepted for publication Feb 25, 2021.

doi: 10.21037/hbsn-21-18

View this article at: http://dx.doi.org/10.21037/hbsn-21-18

Pancreatic ductal adenocarcinoma (PDAC) is a highly aggressive malignancy in which multimodality therapy is necessary to achieve good long-term outcomes. The recent seminar by Mizrahi et al. reported in The Lancet not only summarizes the fundamental knowledge of PDAC but also provides a concise overview of landmark studies that guide modern clinical practice (1). This seminar is especially timely given recent paradigm shifts in treating PDAC as a systemic disease even in early stages. For example, the development of combination regimens such as FOLFIRINOX and gemcitabine with albuminbound paclitaxel have led to not only improved survival in advanced disease but also increased opportunities to downstage some patients with locally advanced tumors by delivering them prior to surgery. In addition, the widespread adoption of a standardized anatomic classification system used to define the local extent of tumor vascular involvement has improved multidisciplinary treatment algorithms which were nicely summarized in this review. Furthermore, exciting developments in the molecular characterization of pancreatic cancer and novel avenues for targeted therapies were reviewed. Overall, Mizrahi et al. present a comprehensive yet clinically focused review on the contemporary pathogenesis, diagnosis, and management of PDAC.

Despite significant advances in systemic therapies for PDAC, the importance of surgery to patient long-term prognosis cannot be over-emphasized. One of the most important advances in the last few decades has been the improved safety of pancreatic surgery. While morbidity rates are still high, postoperative mortality has decreased substantially, particularly at experienced centers. The importance of the volume-outcomes relationship has been clarified in recent years and minimum hospital and surgeon pancreatectomy volumes as well perioperative benchmarks have been defined to optimize clinical outcomes (2). In addition to improved perioperative processes, surgical technique, inpatient resources, and ability to rescue, high volume centers are also more likely to perform minimally invasive pancreatic resection (MIPR). Indeed, MIPR is now the recommended approach for distal pancreatectomy and an acceptable approach especially at high-volume centers for pancreatoduodenectomy (PD) (3).

In addition to perioperative safety, advances in surgical technique as well as increased surgeon specialization have enhanced the oncologic quality of pancreatic surgery. For example, standards have been created that define the appropriate plane of dissection along the superior mesenteric artery as well as the appropriate lymph node stations to remove during PD. Increased attention to the retroperitoneal plane of dissection for DP also led to the design of radical antegrade modular pancreatosplenectomy which can improve margin-clearance and lymphadenectomy in high-risk tumors (4). Importantly, more refined pancreatic surgery does not equate to more radical surgery. Indeed, multiple studies have consistently demonstrated that extended lymphadenectomy or routine vascular resection, for example, does not improve overall survival but increases morbidity, operative time, and length of stay (5). Nevertheless, controversies in pancreatic surgery persist, for example the best practice for postoperative surgical drainage or methods to decrease the rate of postoperative pancreatic fistula.

Improved vascular surgery techniques, patient selection, 
and effective neoadjuvant therapy has also expanded the role of surgery for patients with borderline resectable or locally advanced tumors. In experienced hands, venous resection and reconstruction is safe, feasible, and likely leads to similar oncologic outcomes compared to patients who do not have venous involvement. As a result, pancreatectomy with venous resection has become fairly routine, comprising up to $50 \%$ of PDs in some recent series (6). Arterial resection with pancreatectomy remains controversial both because of increased perioperative morbidity and mortality but also less clear oncologic benefit. Nevertheless, pancreatectomy with arterial resection continues to be performed at experienced centers with acceptable outcomes in order to extend the benefits of surgery to more patients (7). In general, combined venous/arterial resections are performed only in extremely selective cases.

An issue of increasing importance is the timing of surgery. While all patients with PDAC benefit from the receipt of chemotherapy, pancreatic surgery is associated with serious morbidity and as many as $50-60 \%$ of patients who undergo surgical resection never receive the intended adjuvant chemotherapy. Administering systemic therapy in the neoadjuvant setting helps guarantee its delivery even for patients with potentially resectable disease (6). Other advantages of neoadjuvant therapy include the early treatment of micrometastatic disease, improved margin-negative resection rates, decreased lymphnode involvement, improved patient selection for major surgery, and ability to measure response to treatment. In addition, emerging evidence from randomized controlled trials supports a possible overall survival benefit from neoadjuvant therapy in patients with resectable disease (8). Among patients with BR and LA PDAC, neoadjuvant therapy has already become the standard of care given the ability to downstage patients to resectability in $50-70 \%$ and $10-30 \%$, respectively. As systemic therapies become more effective and novel targeted drugs are developed, there will be interest in delivering these agents to patients as early as possible, potentially leading to a paradigm shift of "adjuvant surgery" for more patients. Indeed, some institutions have already reported their experience with total neoadjuvant approach similar to the treatment of patients with rectal cancer (9).

In summary, pancreatic cancer is a highly aggressive malignancy that frequently presents with advanced or metastatic disease. Even among patients with localized disease, though, multimodality therapy with effective surgery, chemotherapy, and radiation are generally necessary to optimize long-term outcomes. While advances in surgery have led to improved outcomes over in recent decades, the development of more effective systemic therapies based on improved molecular approaches to PDAC will be necessary to make further strides in pancreatic cancer care and provide hope to patients with this devastating disease.

\section{Acknowledgments}

Funding: None.

\section{Footnote}

Provenance and Peer Review: This article was commissioned by the editorial office of Hepatobiliary Surgery and Nutrition. The article did not undergo external peer review.

Conflicts of Interest: Both authors have completed the ICMJE uniform disclosure form (available at https://hbsn. amegroups.com/article/view/10.21037/hbsn-21-18/coif). The authors have no conflicts of interest to declare.

Etbical Statement: The authors are accountable for all aspects of the work in ensuring that questions related to the accuracy or integrity of any part of the work are appropriately investigated and resolved.

Open Access Statement: This is an Open Access article distributed in accordance with the Creative Commons Attribution-NonCommercial-NoDerivs 4.0 International License (CC BY-NC-ND 4.0), which permits the noncommercial replication and distribution of the article with the strict proviso that no changes or edits are made and the original work is properly cited (including links to both the formal publication through the relevant DOI and the license). See: https://creativecommons.org/licenses/by-nc-nd/4.0/.

\section{References}

1. Mizrahi JD, Surana R, Valle JW, et al. Pancreatic cancer. Lancet 2020;395:2008-20.

2. Song $\mathrm{Y}$, Shannon AB, Concors SJ, et al. Are Volume Pledge Standards Worth the Travel Burden for Major Abdominal Cancer Operations? Ann Surg 2020. [Epub ahead of print]. doi: 10.1097/SLA.0000000000004361.

3. Asbun HJ, Moekotte AL, Vissers FL, et al. The Miami International Evidence-based Guidelines on Minimally Invasive Pancreas Resection. Ann Surg 2020;271:1-14. 
4. Strasberg SM, Linehan DC, Hawkins WG. Radical antegrade modular pancreatosplenectomy procedure for adenocarcinoma of the body and tail of the pancreas: ability to obtain negative tangential margins. J Am Coll Surg 2007;204:244-9.

5. Dillhoff M, Pawlik TM. Role of Node Dissection in Pancreatic Tumor Resection. Ann Surg Oncol 2021;28:2374-81.

6. Cloyd JM, Katz MH, Prakash L, et al. Preoperative Therapy and Pancreatoduodenectomy for Pancreatic Ductal Adenocarcinoma: a 25-Year Single-Institution Experience. J Gastrointest Surg 2017;21:164-74.

Cite this article as: Brown ZJ, Cloyd JM. Surgery for pancreatic cancer: recent progress and future directions. HepatoBiliary Surg Nutr 2021;10(3):376-378. doi: 10.21037/ hbsn-21-18
7. Loos M, Kester T, Klaiber U, et al. Arterial Resection in Pancreatic Cancer Surgery: Effective After a Learning Curve. Ann Surg 2020. [Epub ahead of print]. doi: 10.1097/SLA.0000000000004054.

8. Cloyd JM, Heh V, Pawlik TM, et al. Neoadjuvant Therapy for Resectable and Borderline Resectable Pancreatic Cancer: A Meta-Analysis of Randomized Controlled Trials. J Clin Med 2020;9:1129.

9. Kim RY, Christians KK, Aldakkak M, et al. Total Neoadjuvant Therapy for Operable Pancreatic Cancer. Ann Surg Oncol 2021;28:2246-56. 